\title{
The role of the endothelin axis and microvessel density in bladder cancer - correlation with tumor angiogenesis and clinical prognosis
}

\author{
EDWIN HERRMANN ${ }^{1}$, MARTIN BÖGEMANN ${ }^{1}$, STEFAN BIERER ${ }^{1}$, ELKE ELTZE ${ }^{2}$, \\ MARIETA I. TOMA ${ }^{3}$, THOMAS KÖPKE ${ }^{1}$, LOTHAR HERTLE $^{1}$ and CHRISTIAN WÜLFING ${ }^{1}$ \\ ${ }^{1}$ Department of Urology and ${ }^{2}$ Institute of Pathology, University of Münster, Albert-Schweitzer Str. 33, 48149 \\ Münster; ${ }^{3}$ Institute of Pathology, University of Dresden, Fetscherstr. 74, 01307 Dresden, Germany
}

Received January 7, 2007; Accepted February 14, 2007

\begin{abstract}
Endothelin-1 (ET-1) and its receptors, entothelin-A $\left(\mathrm{ET}_{\mathrm{A}} \mathrm{R}\right)$ and endothelin-B $\left(\mathrm{ET}_{\mathrm{B}} \mathrm{R}\right)$, commonly referred to as the endothelin (ET)-axis, are involved in tumor biology and growth. We investigated the effects of the ET-axis on microvessel density (MVD) and the clinicopathological parameters of patients with invasive bladder cancer. Paraffin tumor sections of 120 patients who had undergone radical cystectomy were assessed immunohistochemically using mono- and polyclonal antibodies for ET-1, $\mathrm{ET}_{\mathrm{A}} \mathrm{R}, \mathrm{ET}_{\mathrm{B}} \mathrm{R}$ and $\mathrm{CD} 34$ (MVD). Staining intensities were analyzed semiquantitatively and the MVD was calculated as vessels per field. The results were correlated with various pathological and clinical factors, as well as with disease-free and overall survival. Transitional cell carcinomas $(\mathrm{MVD}=23.7)$ were better vascularized than squamous cell carcinomas $(\mathrm{MVD}=17.8, \mathrm{p}=0.04)$. Organconfined tumors $(\mathrm{MVD}=32.2)$ were better vascularized than T3- and T4-tumors (MVD = 21.2, p=0.02) and ET-1 was overexpressed in this subgroup $(\mathrm{p}=0.027)$. Patients with metastatic regional lymph nodes $(\mathrm{MVD}=20.9)$ tended to have less MVD than patients without regional lymph node metastases (MVD = 24.1) $(\mathrm{p}=0.15)$. The account of MVD did not reveal any significant differences in disease-free or overall survival. Organconfined tumors and ET-1 overexpression are associated with upregulated microvessel density. These results suggest that MVD and ET-1 could be considered good prognostic factors.
\end{abstract}

\section{Introduction}

Angiogenesis is the development of new vessels from preexisting vessels. The prognostic value of estimates of angio-

Correspondence to: Dr Edwin Herrmann, Department of Urology, University of Münster, Albert-Schweitzer Strasse 33, 48149 Münster, Germany

E-mail: herrmae@ukmuenster.de

Key words: microvessel density, endothelin axis, angiogenesis, endothelin receptor, endothelin-A, endothelin-B genesis in many types of carcinomas has been investigated since Weidner et al reported that high vascular scores were associated with distant metastases (1). Several groups have investigated the prognostic significance of angiogenesis in bladder cancer using slightly different methods, and in general, it has been concluded that a highly vascular bladder carcinoma behaves more aggressively than a carcinoma with a low vascular density (2-4).

Endothelin (ET)-1, a vasoactive peptide, is produced primarily in endothelial, vascular smooth muscle, and epithelial cells. ET-1 exerts its physiological effect via two high-affinity, $\mathrm{G}$-protein-coupled receptors, endothelin- $\mathrm{A}\left(\mathrm{ET}_{\mathrm{A}} \mathrm{R}\right)$ and endothelin-B $\left(\mathrm{ET}_{\mathrm{B}} \mathrm{R}\right)$. The combination of ET-1 and the two receptors is referred to as the ET-axis, which is associated with tumorigenesis and tumor progression by various mechanisms, including proliferation, invasion, inhibition of apoptosis and angiogenesis (5-8). Conditions of stress such as hypoxia lead to an enhanced production of ET-1. Through $\mathrm{ET}_{\mathrm{B}} \mathrm{R}$, it predominantly stimulates endothelial cell growth, while the induction of vascular smooth muscle cell and pericyte mitogenesis are mediated through $\mathrm{ET}_{\mathrm{A}} \mathrm{R}$ and therefore contribute to the process of angiogenesis in different kinds of tumors $(6,9)$. Although there is not enough data to prove that ET-1 causes angiogenesis directly, this effect is supported by the finding of increased ET-1 expression in ovarian carcinoma (7), colorectal carcinoma (10) and breast cancer (8) in association with an increased expression of VEGF, which in turn stimulates vascular permeability and endothelial cell proliferation by increasing HIF-1 $\alpha$ (7) in a time- and dosedependent manner.

We have recently demonstrated an increased ET-1, $\mathrm{ET}_{\mathrm{A}} \mathrm{R}$ and $\mathrm{ET}_{\mathrm{B}} \mathrm{R}$ expression in bladder carcinomas, the latter being the predominant receptor and associated with a more favorable prognosis (11).

The objective of the present study was to assess whether ET expression is related to angiogenesis in bladder carcinoma. Therefore, this study examined for the first time the expression of the endothelin axis and the angiogenic marker microvessel density (MVD) immunohistochemically in representative paraffin tumor sections. Furthermore, we also assessed the effect of ET expression and MVD on the clinical follow-up. 
Table I. Distribution of pathological and clinical variables in the reported series of bladder cancer specimens $(n=120)$.

Pathological parameters
$(\%)$

$\begin{array}{cc}\text { pT }^{\text {stage }}{ }^{\mathrm{a}} & \\ \text { T1 } & 5(4.2) \\ \text { T2 } & 12(10.2) \\ \text { T3 } & 75(63.6) \\ \text { T4 } & 26(21.7)\end{array}$

$\begin{array}{cc}\mathrm{pN} \text { stage } & \\ \text { N0 } & 78(65) \\ \text { N1 } & 18(15) \\ \text { N2 } & 23(19.2) \\ \text { N3 } & 1(0.8)\end{array}$

cM stage

M0

M1

Histological grade

G1

G2

G3

G4

Histology type

TCC

SCC

Other

$7(5.8)$

${ }^{a}$ In two cases no tumor was found. TCC, transitional cell carcinoma; SCC, squamous cell carcinoma.

\section{Materials and methods}

Patients and tumor specimens. Patients $(\mathrm{n}=120)$ treated with radical cystectomy for invasive bladder cancer at our institution were selected from our bladder cancer database. The 78 men and 42 women underwent surgery between 1989 and 1995; median age at surgery was 62 years (range 33-81). None of the patients had received neo-adjuvant treatment before surgery. Histological slides and formalin-fixed, paraffinembedded tumor tissue blocks from all 120 patients were obtained from the files at the Institute of Pathology. All the slides were reviewed and representative tumor tissue blocks were selected for immunohistochemistry. Histopathological data regarding tumor stage, histological grading and histology type are demonstrated in Table I.

The follow-up assessments with clinical information such as tumor recurrence, progression, overall and disease-free survival and cause of death were evaluated in collaboration with office urologists and were taken from our bladder cancer database (12).
Immunohistochemistry. For immunohistochemical investigations, the paraffin-embedded tumor tissue blocks were cut into 3- $\mu \mathrm{m}$ slices and mounted on poly-L-lysine-coated glass slides. After dewaxing in xylene and rehydrating in a graded series of alcohols, endogenous peroxidase was blocked with $3 \% \mathrm{H}_{2} \mathrm{O}_{2}$. As previously described, staining for $\mathrm{ET}_{\mathrm{A}} \mathrm{R}$ and $\mathrm{ET}_{\mathrm{B}} \mathrm{R}$ was run in a multistep semiautomatic procedure (DAKOAutostainer; DAKO Diagnostics, Hamburg, Germany) (13). The antibodies used were two sheep polyclonal antibodies for $\mathrm{ET}_{\mathrm{A}} \mathrm{R}$ and $\mathrm{ET}_{\mathrm{B}} \mathrm{R}$ (ETAR-Antiserum, Product No. 210506-C250, Affinity Bioregents, Golden, CO, USA), applied at a dilution of 1:100 for $30 \mathrm{~min}$. For ET-1 staining, a monoclonal mouse antibody (Anti-Endothelin-1 MAb, Clone TR.ET.48.5, Affinity Bioreagents) was used. The deparaffinization of the tissue sections was followed by pre-treatment with a steamer (Multi-Gourmet-Steamer, BRAUN, Type 3216) for antigen retrieval (citrate buffer pH 6.0 for $35 \mathrm{~min}$ ). Endogenous peroxidase was blocked; afterwards the primary antibody was applied at a dilution of 1:500 for $25 \mathrm{~min}$ followed by incubation with the secondary antibody (LinkHRP) for $20 \mathrm{~min}$. After the primary antibodies, the sections were incubated with rabbit anti-sheep antibody (DAKO) used as the secondary antibody at a dilution of 1:500 for $25 \mathrm{~min}$. Again, endogenous peroxidase was blocked and then incubated with the Envision Detection Kit for $25 \mathrm{~min}$. The enzyme reaction was developed with Chromogen-DAB ( $2 \times 5 \mathrm{~min})$. The specimens were then counterstained with hematoxylin and mounted with Kaiser's glycerine. The staining intensities of ET-1 and its two receptors on a high-power field (Fig. 1) were classified according to an arbitrary fourtiered scale (negative $=0$, weak $=1$, moderate $=2$, strong $=3$ ) in a manner consistent with previous investigations (13). Weak, moderate, and strong staining patterns were defined as positive in the subsequent statistical analysis.

CD34 immunohistochemistry was performed as published previously (14). The Class II Clone QBEnd 10 mouse antihuman monoclonal antibody was used (DAKO, Carpenteria, CA, USA). The antigen was unmasked by microwave heating of the slides three times for $5 \mathrm{~min}$ in citrate buffer ( $\mathrm{pH}$ 6.0). After washing in PBS, the primary antibody was applied for $1 \mathrm{~h}$ at room temperature. For the detection system, LSAB2 (DAKO, K0675) was used with the secondary antibody as the biotinylated link $(30 \mathrm{~min})$ followed by streptavidinperoxidase (30 min). After every step, the slides were washed in PBS ( $\mathrm{pH}$ 7.4). The reaction was detected by incubating with diaminobenzidine for $5 \mathrm{~min}$. After counterstaining with $\mathrm{H} \& \mathrm{E}$, the slides were dehydrated, clarified and mounted. The stained vessels were counted in five consecutive fields from the representative tumor zone and the mean value considered as the MVD.

Data analysis. Staining intensity was evaluated semiquantitatively in a blind fashion. For statistical analysis SPSS for Windows (Version 13.0) was used. All the histopathological parameters were correlated with the staining results by means of cross-tables, applying the Kruskal-Wallis test. The Kaplan-Meier method was used to derive the recurrence-free survival and the log-rank test to compare curves for two or more groups. For multivariate analysis of the prognostic factors, a Cox regression analysis was 


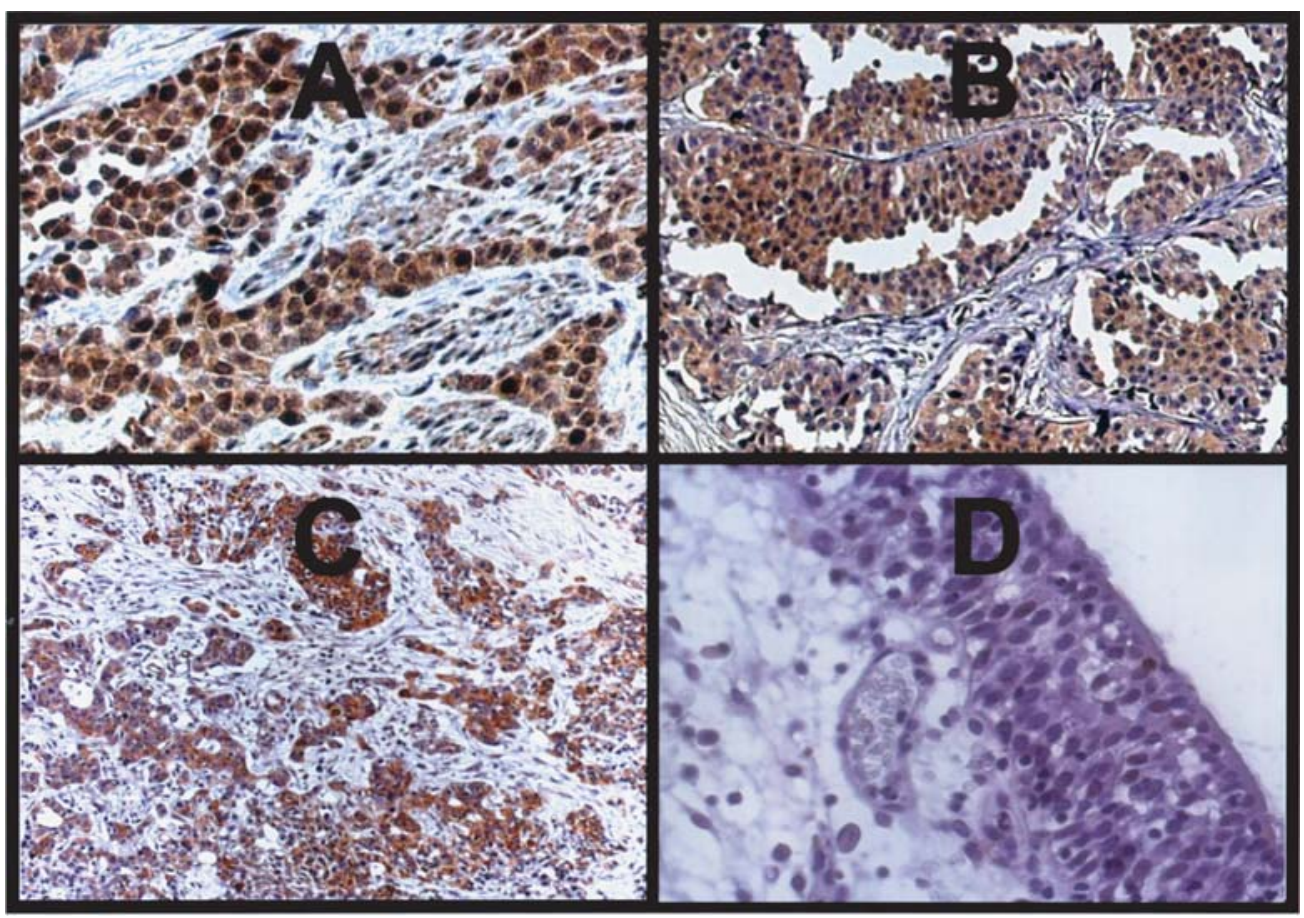

Figure 1. Representative examples of staining for endothelin-1 (A), and its receptors, endothelin-A (B) and endothelin-B (C), in invasive carcinoma of the bladder and negative staining in a normal urothelium (D).

performed. A p-value of $\mathrm{p}<0.05$ indicated significant differences between the groups

\section{Results}

From the 120 patients, the ET-1, $\mathrm{ET}_{\mathrm{A}} \mathrm{R}$ and $\mathrm{ET}_{\mathrm{B}} \mathrm{R}$ staining status was available in $117(97.5 \%)$ cases. In some of the specimens, tissue had been lost during steamer-pretreatment. The staining intensity of ET-1, $\mathrm{ET}_{\mathrm{A}} \mathrm{R}$, and $\mathrm{ET}_{\mathrm{B}} \mathrm{R}$ among the different samples varied from the complete absence of staining to strong staining. Endothelin-1 staining was identified in $26.5 \%$ of the cases, $\mathrm{ET}_{\mathrm{A}} \mathrm{R}$ in $60.7 \%$ and $\mathrm{ET}_{\mathrm{B}} \mathrm{R}$ in $78.6 \%$, respectively.

For vascular markers, CD34 staining gave a mean MVD of 21.5 for all the investigated tumors. Transitional carcinomas were better vascularized than squamous cell carcinomas $(\mathrm{MVD}=23.7$ and MVD $=17.8$, respectively; $\mathrm{p}=0.04)$. Organconfined tumors were better vascularized than T3- and T4tumors $(\mathrm{MVD}=32.2$ and $\mathrm{MVD}=21.2$, respectively; $\mathrm{p}=0.02$ ) and ET-1 was overexpressed in this subgroup $(\mathrm{p}=0.027)$. There was no association of MVD to histological grading $(\mathrm{p}=0.47)$, or metastases $(\mathrm{p}=0.37)$. However, patients with metastatic regional lymph nodes $(\mathrm{MVD}=20.9)$ tended to have less MVD than patients without regional lymph node metastases $(M V D=24.1, p=0.15)$, although this difference was not significant. Tumors with negative ET-1, $\mathrm{ET}_{\mathrm{A}} \mathrm{R}$ and $\mathrm{ET}_{\mathrm{B}} \mathrm{R}$ staining had an MVD of 21.7, 21.8 and 23.6, those with faint or positive expression $26.6(\mathrm{p}=0.30), 23.1(\mathrm{p}=0.29)$ and $23.5(\mathrm{p}=0.37)$, respectively. A comprehensive summary of the distribution of MVD and its association with clinicopathological parameters and the endothelin axis is given in Table II.

All patients were followed-up for a minimum of 41 months (median, 86; range, 41-170). The median overall survival and disease-free survival times were 24 months [95\% Confidence Interval (CI), 17-31 months] and 20 months (95\% CI, 13-27 months), respectively. Eighty (66.7\%) patients had died of either tumor-related $(n=67)$ or other $(n=13)$ causes. Three patients have recently been diagnosed with local tumor recurrence or metastasis, 33 show no evidence of disease and 4 have been lost to the follow-up.

With the Kaplan-Meier survival analysis and log-rank test for the comparison of the survival curves, the stratification of patients according to MVD > 21.5 (mean value) and MVD < 21.5 did not reveal any significant differences in disease-free or overall survival (Fig. 2).

A multivariate analysis using Cox-regression analysis was performed (Table III). Only tumor stage $(\mathrm{p}=0.003)$ and metastatic disease were independent prognostic parameters $(\mathrm{p}<0.001)$, but not MVD.

\section{Discussion}

There is increasing evidence for the emerging role of the ETaxis in several tumor types. Experimental and epidemiological studies have shown that tumor development can be reduced by inhibitors of the ET-axis, which block various mechanisms of tumor growth such as proliferation, invasion, inhibition of apoptosis and angiogenesis $(5,6,15,16)$. In some tumor types, ET-1 production is associated with an increased expression of VEGF and neovascularization, which in turn stimulates vascular permeability and endothelial cell proliferation by increasing HIF-1 $\alpha(7 ; 13)$. Endothelial cell growth is stimulated predominantly through $\mathrm{ET}_{\mathrm{B}} \mathrm{R}$, while the induction of vascular smooth muscle cell and pericyte mitogenesis is mediated through $\mathrm{ET}_{\mathrm{A}} \mathrm{R}(9,17)$. In brain tumors, ET-1 expression is correlated with transforming growth factor $\beta 1$-expression and 
Table II. Mean value of MVD and the expression of ET-1, $\mathrm{ET}_{\mathrm{A}} \mathrm{R}$ and $\mathrm{ET}_{\mathrm{B}} \mathrm{R}$.

\begin{tabular}{|c|c|c|c|c|c|c|c|}
\hline $\begin{array}{l}\text { Pathological } \\
\text { variables } \\
\text { pT stage }\end{array}$ & $\begin{array}{c}\text { MVD n } \\
\text { (mean value) }\end{array}$ & \multicolumn{2}{|c|}{$\begin{array}{l}\text { ET-1 staining n } \\
\text { positive total (\%) }\end{array}$} & \multicolumn{2}{|c|}{$\begin{array}{l}\mathrm{ET}_{\mathrm{A}} \mathrm{R} \text { staining } \mathrm{n} \\
\text { positive/total }(\%)\end{array}$} & \multicolumn{2}{|c|}{$\begin{array}{l}\mathrm{ET}_{\mathrm{B}} \mathrm{R} \text { staining } \mathrm{n} \\
\text { positive/total }(\%)\end{array}$} \\
\hline $\mathrm{T} 1$ & 29.9 & $1 / 5$ & $(20)$ & $2 / 5$ & $(40)$ & $4 / 5$ & (80) \\
\hline $\mathrm{T} 2$ & 33.2 & $5 / 12$ & $(41.7)$ & $10 / 12$ & $(83.3)$ & $11 / 12$ & (91.7) \\
\hline T3 & 21.2 & $17 / 72$ & $(23.6)$ & $44 / 73$ & $(60.3)$ & $56 / 73$ & (76.7) \\
\hline $\mathrm{T} 4$ & 21.4 & $7 / 26$ & $(26.9)$ & $14 / 26$ & $(53.8)$ & $20 / 26$ & (76.9) \\
\hline \multicolumn{8}{|l|}{ pN stage } \\
\hline No & 24.1 & $23 / 76$ & $(30.3)$ & $45 / 76$ & $(59.2)$ & $60 / 76$ & (79.8) \\
\hline $\mathrm{N} 1$ & 20.6 & $1 / 17$ & $(5.9)$ & $10 / 17$ & $(58.8)$ & $16 / 17$ & (94.1) \\
\hline $\mathrm{N} 2$ & 21.3 & $7 / 23$ & $(30.4)$ & $15 / 23$ & $(65.2)$ & $15 / 23$ & $(65.2)$ \\
\hline N3 & 17.4 & $0 / 1$ & (0) & $1 / 1$ & $(100)$ & $1 / 1$ & (100) \\
\hline \multicolumn{8}{|l|}{ cM stage } \\
\hline M0 & 23.1 & $31 / 112$ & $2(27.7)$ & $68 / 112$ & $(60.7)$ & $89 / 112$ & (79.5) \\
\hline M1 & 20.7 & $0 / 5$ & $(0)$ & $3 / 5$ & $(60)$ & $3 / 5$ & (60) \\
\hline \multicolumn{8}{|c|}{ Histological grade } \\
\hline G1 & 22.9 & $2 / 3$ & $(66.7)$ & $2 / 3$ & $(66,7)$ & $1 / 2$ & $(50.0)$ \\
\hline G2 & 20.8 & $4 / 21$ & $(21)$ & $14 / 22$ & (63.6) & $17 / 22$ & (77.3) \\
\hline G3 & 23.4 & $24 / 89$ & (27) & $53 / 88$ & $(60.2)$ & $71 / 89$ & (79.8) \\
\hline G4 & 25.9 & $1 / 4$ & $(25)$ & $2 / 4$ & $(50)$ & $3 / 4$ & (75) \\
\hline \multicolumn{8}{|c|}{ Histology type } \\
\hline TCC & 23.7 & 24/97 & $(24.7)$ & $60 / 98$ & $(61.2)$ & $76 / 97$ & (78.4) \\
\hline SCC & 17.8 & $4 / 13$ & $(30.8)$ & $8 / 13$ & $(61.5)$ & $11 / 13$ & (84.6) \\
\hline Other & 22.8 & $3 / 7$ & (42.9) & $3 / 6$ & $(50)$ & $5 / 7$ & (71.4) \\
\hline
\end{tabular}

MVD, microvessel density; ET-1, endothelin-1; $\mathrm{ET}_{\mathrm{A}} \mathrm{R}$, endothelin-A receptor; $\mathrm{ET}_{\mathrm{B}} \mathrm{R}$, endothelin-B receptor; $\mathrm{TCC}$, transitional cell carcinoma; SCC, squamous cell carcinoma.

tumor vascularity (18). These preclinical data indicate that the ET-axis is involved in the process of angiogenesis and can accelerate neovascularization in malignancies. For bladder carcinoma there is not enough data to confirm these results - the role of the ET-axis and its direct influence on angiogenesis is still unclear.

Some authors have highlighted that a highly vascular bladder carcinoma behaves more aggressively than a carcinoma with a low vascular density and is associated with a less favorable prognosis (2-4). Few studies have demonstrated the relationship of angiogenesis with improvement in survival $(19,20)$. Offersen et al were able to show a positive correlation between inflammation in bladder carcinoma, angiogenic factors and good prognosis. In particular, patients with an increasing degree of inflammation in the tumor were associated with a survival improvement, which could reflect the ability of the patient to mount an immune response (21).

Only two studies have been published that deal with the same angiogenic marker (CD34) as used in our study in order to estimate angiogenesis in cystectomy specimens, identifying MVD as an independent parameter of poor prognosis $(2,4)$. Both studies determined MVD by estimating the number of microvessels in the most vascular areas (so-called 'hot spots') previously described by Weidner et al (1). As the main goal of our present study was to compare the local expression of the investigated markers within different areas of representative tumor tissue, we counted the stained vessels in five consecutive fields and considered the mean value as the MVD.

In a former study, we were able to demonstrate the expression of ET-1 and both of its receptors, $\mathrm{ET}_{\mathrm{A}} \mathrm{R}$ and $\mathrm{ET}_{\mathrm{B}} \mathrm{R}$, in bladder cancer patients who had undergone radical cystectomy. ET-1 and $\mathrm{ET}_{\mathrm{A}} \mathrm{R}$ expression were not correlated with pathological and clinical parameters or with survival curves. However, $\mathrm{ET}_{\mathrm{B}} \mathrm{R}$ expression was associated with more favorable tumor types (11).

The objective of the current study was to clarify whether the expression of the ET-axis has any influence on angiogenesis and whether upregulated MVD has a prognostic value for bladder cancer patients. A directly proportional increase in the expression of the ET-axis and MVD associated with a poor prognosis was the expected outcome of the study. Applying standard immunohistochemical techniques, we showed upregulated MVD in organ-confined tumors. Furthermore, we demonstrated the overexpression of ET-1 in 

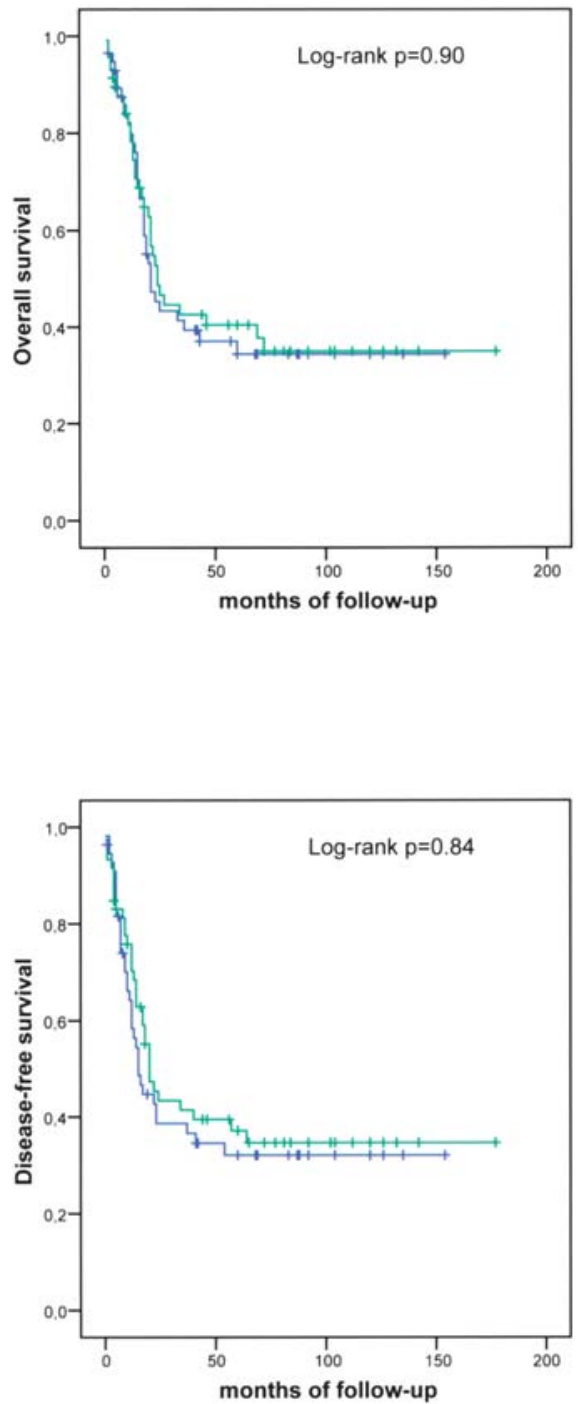

Figure 2. Overall survival and disease-free survival time in 120 bladder cancer patients in relation to microvessel density (MVD) $>21.5$ (green line) and MVD $<21.5$ (blue line).

this subgroup compared to T3- and T4-tumors. Patients with regional lymph node metastases tended to have less MVD compared to patients without metastatic lymph nodes, although statistically this was not significant. Patients with transitional carcinoma of the bladder had more MVD compared to patients with squamous cell carcinoma. All these suprising results suggest the possibility of a good prognosis for patients with upregulated MVD. However, with the Kaplan-Meier survival analysis and log-rank test for the comparison of the survival curves, the stratification of patients according to MVD did not reveal any significant differences in disease-free or overall survival. In the multivariate analysis, only the tumor stage and metastatic disease were considered independent prognostic parameters, but not MVD.

In 1979, Mihatsch et al were the first to report a significantly better 1-year survival when lymphocytes, plasma cells and/or lymph follicles were present in invasive carcinoma of the bladder (22). Flamm was able to confirm these results in superficial bladder carcinoma, reporting that about 428 patients with an inflammatory reaction in their tumor experienced significantly fewer recurrences and cancer-related deaths
Table III. Multivariate analysis of prognostic factors in 120 bladder cancer patients.

\begin{tabular}{|c|c|c|}
\hline \multirow[t]{2}{*}{$\begin{array}{l}\text { Prognostic } \\
\text { variables }\end{array}$} & \multicolumn{2}{|c|}{$\begin{array}{l}\text { Overall survival, } \\
\text { all patients }(\mathrm{n}=120)\end{array}$} \\
\hline & $\begin{array}{l}\text { Risk } \\
\text { ratio }\end{array}$ & $\begin{array}{c}\text { Statistical } \\
\text { significance }\end{array}$ \\
\hline MVD & 0.634 & 0.433 \\
\hline ET-1 & 1.120 & 0.900 \\
\hline $\mathrm{ET}_{\mathrm{A}} \mathrm{R}$ & 0.975 & 0.853 \\
\hline $\mathrm{ET}_{\mathrm{B}} \mathrm{R}$ & 0.658 & 0.128 \\
\hline $\mathrm{T}$ & 3.073 & 0.003 \\
\hline $\mathrm{N}$ & 0.707 & 0.688 \\
\hline M & 4.098 & $<0.001$ \\
\hline G & 2.878 & 0.058 \\
\hline Histology type & 1.098 & 0.974 \\
\hline
\end{tabular}

MVD, microvessel density; ET-1, endothelin-1; $\mathrm{ET}_{\mathrm{A}} \mathrm{R}$, endothelin-A receptor; $\mathrm{ET}_{\mathrm{B}} \mathrm{R}$, endothelin- $\mathrm{B}$ receptor; $\mathrm{T}$, tumor stage; $\mathrm{N}$, lymph node stage; $\mathrm{M}$, metastases; $\mathrm{G}$, histological grade.

compared to those without inflammation (23). In another study, Offersen et al showed a survival advantage for patients with intense inflammation in their tumors with a correlation to significantly increased vascular density. MVD was very closely associated to the degree of inflammation and even represented an independent parameter for better survival using overall death as the end-point. The survival advantage was described to reflect a host vs tumor response (20).

Taking these results into account, upregulated MVD in our series, as described in organ-confined tumors, could be due to the angiogenetic stimulation of a local inflammatory reaction generated by the host against the cystectomy specimens. As ET-1 was overexpressed in these specimens and is associated with neovascularization and VEGF expression in various human tumors, it could be involved in the regulation of angiogenesis in bladder cancer. Its loss could lead to a diminished differentiation and an association with unfavorable parameters, such as higher tumor stages, higher histological grades and tumor progression.

In summary, we have shown that ET-1 and its receptors are expressed by bladder carcinoma cells, and that the expression of ET-1 positively correlates with angiogenesis defined as microvessel density in organ-confined tumors. These results suggest that MVD could be considered a good prognostic factor. However, angiogenesis is not yet considered a useful prognostic marker for time to progression or overall survival in patients with invasive carcinoma of the bladder.

\section{References}

1. Weidner N, Semple JP, Welch WR and Folkman J: Tumor angiogenesis and metastasis-correlation in invasive breast carcinoma. N Engl J Med 324: 1-8, 1991.

2. Bochner BH, Cote RJ, Weidner N, et al: Angiogenesis in bladder cancer: relationship between microvessel density and tumor prognosis. J Natl Cancer Inst 87: 1603-1612, 1995. 
3. Philp EA, Stephenson TJ and Reed MW: Prognostic significance of angiogenesis in transitional cell carcinoma of the human urinary bladder. Br J Urol 77: 352-357, 1996.

4. Inoue K, Slaton JW, Karashima T, et al: The prognostic value of angiogenesis factor expression for predicting recurrence and metastasis of bladder cancer after neoadjuvant chemotherapy and radical cystectomy. Clin Cancer Res 6: 4866-4873, 2000.

5. Nelson J, Bagnato A, Battistini B and Nisen P: The endothelin axis: emerging role in cancer. Nat Rev Cancer 3: 110-116, 2003.

6. Herrmann E, Bogemann M, Bierer S, Eltze E, Hertle L and Wulfing C: The endothelin axis in urologic tumors: mechanisms of tumor biology and therapeutic implications. Exp Review Anticancer Ther 6: 73-81, 2006.

7. Spinella F, Rosano L, Di Castro V, Natali PG and Bagnato A: Endothelin-1 induces vascular endothelial growth factor by increasing hypoxia-inducible factor-1alpha in ovarian carcinoma cells. J Biol Chem 277: 27850-27855, 2002.

8. Wulfing P, Kersting C, Tio J, et al: Endothelin-1-, endothelin-A-, and endothelin-B-receptor expression is correlated with vascular endothelial growth factor expression and angiogenesis in breast cancer. Clin Cancer Res 10: 2393-2400, 2004.

9. Bek EL and McMillen MA: Endothelins are angiogenic. J Cardiovasc Pharmacol 36: 135-139, 2000.

10. Shankar A, Loizidou M, Aliev G, et al: Raised endothelin 1 levels in patients with colorectal liver metastases. Br J Surg 85: 502-506, 1998.

11. Wulfing C, Eltze E, Yamini J, et al: Expression of the endothelin axis in bladder cancer: relationship to clinicopathologic parameters and long-term survival. Eur Urol 47: 593-600, 2005.

12. Wulfing C, Eltze E, Piechota $\mathrm{H}$, et al: Expression of endothelin1 and endothelin-A and -B receptors in invasive bladder cancer. Oncol Rep 13: 223-228, 2005.

13. Wulfing P, Diallo R, Kersting C, et al: Expression of endothelin-1, endothelin- $\mathrm{A}$, and endothelin-B receptor in human breast cancer and correlation with long-term follow-up. Clin Cancer Res 9: 4125-4131, 2003.
14. Friedrich MG, Toma MI, Petri S, et al: Expression of Maspin in non-muscle invasive bladder carcinoma: correlation with tumor angiogenesis and prognosis. Eur Urol 45: 737-743, 2004.

15. Nelson JB: Endothelin inhibition: novel therapy for prostate cancer. J Urol 170: 65-67, 2003.

16. Carducci MA, Padley RJ, Breul J, et al: Effect of endothelin-A receptor blockade with atrasentan on tumor progression in men with hormone-refractory prostate cancer: a randomized, phase II, placebo-controlled trial. J Clin Oncol 21: 679-689, 2003.

17. Salani D, Di Castro V, Nicotra MR, et al: Role of endothelin-1 in neovascularization of ovarian carcinoma. Am J Pathol 157: $1537-1547,2000$.

18. Stiles JD, Ostrow PT, Balos LL, et al: Correlation of endothelin-1 and transforming growth factor beta 1 with malignancy and vascularity in human gliomas. J Neuropathol Exp Neurol 56: 435-439, 1997.

19. Bartoletti R, Cai T, Nesi G, Sardi I and Rizzo M: Qualitative and quantitative analysis of angiogenetic factors in transitional cell bladder carcinoma: relationship with clinical course at 10 years follow-up. Oncol Rep 14: 251-255, 2005.

20. Offersen BV, Borre M and Overgaard J: Quantification of angiogenesis as a prognostic marker in human carcinomas: a critical evaluation of histopathological methods for estimation of vascular density. Eur Urol 39: 881-890, 2003.

21. Offersen BV, Knap MM, Marcussen N, Horsman MR, Hamilton-Dutoit S and Overgaard J: Intense inflammation in bladder carcinoma is associated with angiogenesis and indicates good prognosis. Br J Cancer 87: 1422-1430, 2002.

22. Mihatsch MJ, Rist M, Romppanen T and Rutishauser G Prognostic significance of peritumoural inflammation in invasive urothelial bladder carcinoma. Urol Res 7: 97-102, 1979.

23. Flamm J: Tumor-associated tissue inflammatory reaction and eosinophilia in primary superficial bladder cancer. Urology 40 : 180-185, 1992. 